\title{
Solution of the connected problem of thermomechanics for a long hollow electroconductive cylinder under the action of impulsed electromagnetic field with amplitude modulation
}

\author{
Musij R., Drohomyretska Kh., Klapchuk M., Oryshchyn O., Nakonechnyy R. \\ Lviv Polytechnic National University, \\ 12 S. Bandera Str., 79013, Lviv, Ukraine
}

(Received 16 June 2018)

\begin{abstract}
Using the approximation of the distributions of the axial component of the magnetic field stress vector, of temperature and radial displacements in the radial variable by cubic polynomials, we obtain a general solution of the connected dynamic problem of thermomechanics for an electric conductive hollow cylinder under the action of impulsed electromagnetic fields with amplitude modulation of characteristic types in modes with the impulsed modular signal, the damped sinusoid and the single electromagnetic impulse equal to the modular signal.
\end{abstract}

Keywords: impulsive electromagnetic field with amplitude modulation, mode with impulse modular signal, damped sinusoid mode, single electromagnetic impulse, electroconductive hollow cylinder, connected problem of thermomechanics, cubic approximation.

2000 MSC: $74 \mathrm{H} 10$

UDC: 539.3

DOI: $10.23939 / \mathrm{mmc} 2018.01 .048$

\section{Introduction}

Impulse electromagnetic fields (IEMF) are widely used in modern technologies of impulsed electromagnetic processing of materials, in various kinds of tomographs for layer scanning of biological objects, and others like that [1-3]. An important place among IEMF is occupied by IEMF with amplitude modulation. Some works [4-6] on the determination of the thermo-stressed state of conductive bodies of a canonical form under the action of stationary EMF and IEMF with amplitude modulation in the formulation of an unconnected problem of thermomechanics for such bodies are known from the literature. However, the influence of the process of thermoelastic energy dissipation under the action of IEMF with amplitude modulation on the thermo-elastic state of the electro-conductive cylinder is insufficiently studied.

In the present work, using the proposed in $[6,7]$ method which apply the cubic approximation of distributions of defining functions in a radial variable, we construct a general solution to the connected problem of thermomechanics for a long hollow electroconductive cylinder under the action of a impulse electromagnetic field with amplitude modulation.

\section{Mathematical description of characteristic types of impulsed EMF with the modu- lation of amplitude}

An impulse EMF with amplitude modulation is given on the inner $r=r_{0}$ and outer $r=r_{1}$ surfaces of the cylinder considered by the values $H_{z}^{ \pm}(t)$ of the tangential axial component $H_{z}(r, t)$, which are described by the dependence [5]

$$
H_{z}{ }^{ \pm}(t)=H_{0} \varphi_{0}(t) \sin (\omega t+\varphi)
$$


where $\varphi_{0}(t)$ is a function that modulates the signal of carrier electromagnetic oscillations of frequency $\omega$.

Characteristic types of IEMP with amplitude modulation are IEMP in modes - with pulse modular signal (RIMS) and damped sinusoids (RDS), as well as a single electromagnetic impulse (EMI) corresponding to the modulus impulse $\varphi_{0}(t)$ of IEMP at RIMS for frequency $\omega=0$. For these characteristic types of IEMP we have:

for an action in RIMS (see Fig. 1), the function $\varphi_{0}(t)$ will be equal to

$$
\varphi_{0}(t)=k_{0}\left(e^{-\beta_{1} t}-e^{-\beta_{2} t}\right),
$$

for the action in RDS (see Fig. 2), this function has the form

$$
\varphi_{0}(t)=k_{1} e^{-\beta t}
$$

Here $H_{0}$ is the maximum value of the strength of the magnetic field on the surfaces of the cylinder, $\varphi$ is the initial phase, $k_{0}$ and $k_{1}$ are the normalization factors, $\beta_{1}$ and $\beta_{2}$ are the parameters characterizing the times of the fronts of the rise and the fall of the module impulse, $\beta$ is the parameter characterizing the time of damping practically to zero of the amplitude of the sinusoidal electromagnetic oscillations. Note that if we take frequency $\omega \equiv 0$ in the formula (1) for action in RIMS, we obtain a mathematical description of EMI (see Fig. 3).

For the convenience of further mathematical transformations, we present the expression (1) in the following complex form

$$
H_{z}^{ \pm}(t)=\sum_{k=1}^{N} A_{k} e^{b_{k} t}
$$

where for action in RIMS we have:

$$
\begin{gathered}
N=4, \quad A_{1}=A_{2}=1 / 2, \quad A_{3}=A_{4}=-1 / 2 \\
b_{1}=-\beta_{1}-i \omega, \quad b_{2}=-\beta_{1}+i \omega, \quad b_{3}=-\beta_{2}-i \omega, \quad b_{4}=-\beta_{2}+i \omega
\end{gathered}
$$

and for action in RDS we take:

$$
\begin{gathered}
N=2, \quad A_{1}=1 / 2 i, \quad A_{3}=-1 / 2 i, \\
b_{1}=-\beta-i \omega, \quad b_{2}=-\beta+i \omega .
\end{gathered}
$$

In these expressions, the value $i$ is an imaginary unit.

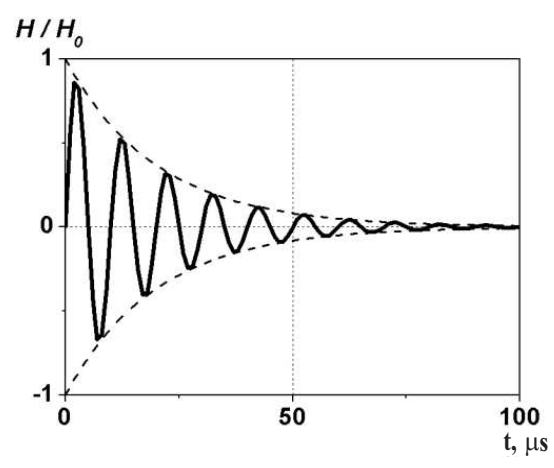

Fig. 1. Impulse electromagnetic action in RIMS in time duration $t_{i}=100 \mu s$.

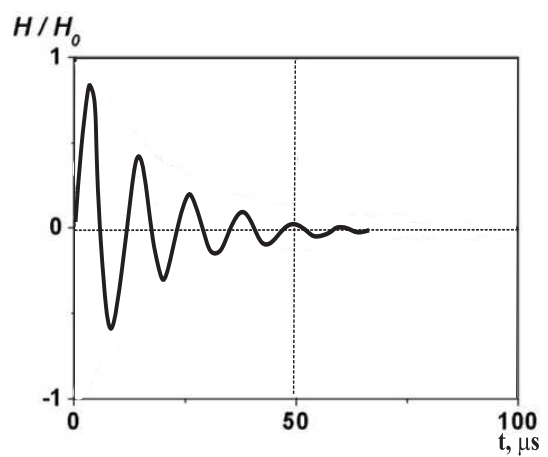

Fig. 2. Impulse electromagnetic action in RDS in time duration $t_{i}=100 \mu s$.

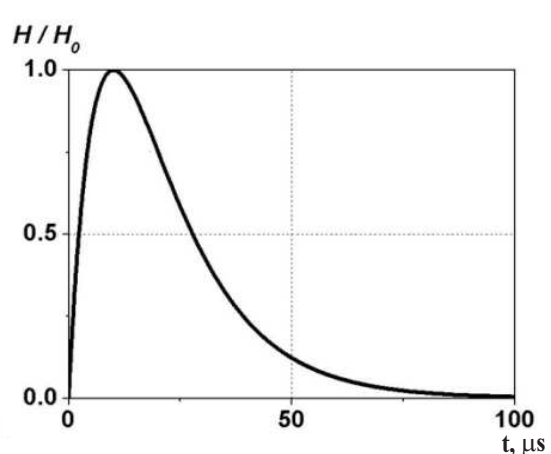

Fig. 3. Impulse electromagnetic action in EMI in time duration $t_{i}=100 \mu s$. 


\section{Formulation of the connected thermomechanics problem for a long hollow electro- conductive cylinder}

Consider a long hollow electroconductive cylinder, referred to a cylindrical system of coordinates $(r, \varphi, z)$, whose axis $O z$ coincides with the axis of symmetry of the cylinder. The material of the cylinder is homogeneous, isotropic and non-ferromagnetic, and its physical and mechanical characteristics are constant.

The cylinder is under the action of a non-stationary EMF, which is given by the values of the axial component $H_{z}$ of the magnetic field stress vector $\vec{H}(r, t)$ on the inner $r=r_{0}$ and outer $r=r_{1}$ surfaces of the cylinder

$$
H_{z}\left(r_{0}, t\right)=H_{z}^{-}(t), \quad H_{z}\left(r_{1}, t\right)=H_{z}^{+}(t)
$$

Here $H_{z}^{ \pm}(t)$ are the given functions of time $t$. The surfaces of the cylinder $r=r_{0}$ and $r=r_{1}$ are heat-insulated and free of power loading.

Under such conditions, the calculated model for determining the thermo-stressed state of the cylinder consists of two stages [7]: at the first stage, from the equations of electrodynamics, the vector of magnetic field stress $\vec{H}$ in the cylinder and the predetermined by it Joule heat ejection $Q$ and ponderomotive forces $\vec{F}$ are determined; and at the second stage from the equations of the connected dynamic problem of thermoelasticity, the temperature field $T$ and the radial component $U_{r}(r, t)$ of the displacement vector $\vec{U}=\left\{U_{r}(r, t) ; 0 ; 0\right\}$ and the corresponding components $\sigma_{j j}(j=r, \varphi, z)$ of the stress tensor $\hat{\sigma}$ are determined.

On the basis of Maxwell's relations the different from zero axial component $H_{z}(r, t)$ of the magnetic field stress vector $\vec{H}=\left\{0 ; 0 ; H_{z}(r, t)\right\}$ is determined from the equation

$$
\frac{\partial^{2} H_{z}}{\partial r^{2}}+\frac{1}{r} \frac{\partial H_{z}}{\partial r}-\sigma \mu \frac{\partial H_{z}}{\partial t}=0
$$

under the boundary condition (1) and the zero initial condition

$$
H_{z}(r, 0)=0 .
$$

Here $\sigma$ is the coefficient of electrical conductivity, $\mu$ is the magnetic penetrability of the material of the cylinder.

Basing on the obtained function $H_{z}(r, t)$, the specific densities of Joule heat ejection $Q(r, t)$ and ponderomotive force $\vec{F}=\left\{F_{r}(r, t) ; 0 ; 0\right\}$ are given by the relations

$$
Q=\frac{1}{\sigma}\left(\frac{\partial H_{z}}{\partial r}\right)^{2}, \quad F_{r}=-\mu H_{z} \frac{\partial H_{z}}{\partial r}
$$

The temperature $T(r, t)$ and the radial component $U_{r}(r, t)$ of the displacement vector are found from the system of equations for the connected dynamic problem of thermomechanics for a cylinder

$$
\begin{gathered}
\frac{\partial^{2} T}{\partial r^{2}}+\frac{1}{r} \frac{\partial T}{\partial r}-\frac{1+\varepsilon_{*}}{\varkappa} \frac{\partial T}{\partial t}-\varepsilon_{*} \frac{1+2 \nu}{\varkappa \alpha E} \cdot \frac{\partial^{2} U_{r}}{\partial t \partial r}=-\frac{1}{\lambda} Q, \\
\frac{\partial^{2} U_{r}}{\partial r^{2}}+\frac{1}{r} \frac{\partial U_{r}}{\partial r}-\frac{U_{r}}{r^{2}}-\frac{1}{c^{2}} \frac{\partial^{2} U_{r}}{\partial t^{2}}=\alpha \frac{1+\nu}{1-\nu} \frac{\partial T}{\partial r}-\frac{(1+\nu)(1-2 \nu)}{E(1-\nu)} F_{r} .
\end{gathered}
$$

Here $\varkappa, \lambda, \nu, \alpha$ are coefficients of temperature and heat conductivity, Poisson, linear thermal expansion, $E$ is Young's modulus, $\rho$ is the cylinder material density; $c=\sqrt{E(1-\nu) /(\rho(1+\nu)(1-2 \nu))}$ is the velocity of the elastic wave of expansion; $\varepsilon_{*}$ is a parameter that characterize the connectivity of deformation and temperature fields. 
The system (9) is solved under the boundary conditions

$$
\frac{\partial T\left(r_{0}, t\right)}{\partial r}=0, \quad \frac{\partial T\left(r_{1}, t\right)}{\partial r}=0,
$$

of thermal insulation of surfaces $r=r_{0}$ and $r=r_{1}$ and conditions

$$
\begin{aligned}
& \frac{\partial U_{r}\left(r_{0}, t\right)}{\partial r}+\frac{\nu}{1-\nu} \frac{U_{r}\left(r_{0}, t\right)}{r_{0}}=\alpha \frac{1+\nu}{1-\nu} T\left(r_{0}, t\right), \\
& \frac{\partial U_{r}\left(r_{1}, t\right)}{\partial r}+\frac{\nu}{1-\nu} \frac{U_{r}\left(r_{1}, t\right)}{r_{1}}=\alpha \frac{1+\nu}{1-\nu} T\left(r_{1}, t\right)
\end{aligned}
$$

of absence of power loading on these surfaces, and also zero initial conditions

$$
T(r, 0)=0, \quad U_{r}(r, 0)=0, \quad \frac{\partial U_{r}(r, 0)}{\partial r}=0 .
$$

For the obtained functions $T(r, t), U_{r}(r, t)$, the radial $\sigma_{r r}$, circle $\sigma_{\varphi \varphi}$, and axial $\sigma_{z z}$ components of the stress tensor are determined by the formulas.

$$
\begin{gathered}
\sigma_{r r}=\frac{2 E}{1-2 \nu}\left[(1-\nu) \frac{\partial U_{r}}{\partial r}+\nu \frac{U_{r}}{r}-\alpha(1+\nu) T\right] \\
\sigma_{\varphi \varphi}=\frac{2 E_{n}}{1-2 \nu}\left[(1-\nu) \frac{U_{r}}{r}+\nu \frac{\partial U_{r}}{\partial r}-\alpha(1+\nu) T\right] \\
\sigma_{z z}=\nu\left(\sigma_{r r}+\sigma_{\varphi \varphi}\right)-\alpha E(1+\nu) T .
\end{gathered}
$$

\section{Methodology for constructing a solution}

To construct the solutions of the initial boundary-value problems of the electrodynamics (5)-(7) and the connected problem of thermoelasticity (9)-(12), we use the approximation of the key functions over the radial variable by cubic polynomials $[6,7]$ :

$$
\Phi(r, t)=\sum_{i=0}^{3} a_{i}(t) r^{i} .
$$

The coefficients $a_{i}(t)$ of approximation polynomials (14) are given as a linear combination

$$
a_{i}(t)=a_{i 1} \Phi_{1}(t)+a_{i 2} \Phi_{2}(t)+a_{i 3} \Phi^{+}(t)+a_{i 4} \Phi^{-}(t)+a_{i 5} \Phi_{0}(t)
$$

of the boundary values $\Phi^{ \pm}(t)$ of the desired functions on the surfaces $r=r_{0}$ and $r=r_{1}$, and the integral characteristics

$$
\Phi_{s}(t)=\int_{r_{0}}^{r_{1}} \Phi(r, t) r^{s} d r
$$

of the key functions.

Equations for integral characteristics $\Phi_{s}(t)$ are obtained by integrating the equations (6), (9) according to formula (16) and by using expressions (10), (11) for analytic transformations.

On the basis of the proposed methodics, described in detail in [7], we find solutions to the problem under consideration under action of the IEMF with amplitude modulation of the characteristic types described by expression (4). 


\section{The solution of the problem under the action of impulsed EMF with amplitude modulation of characteristic types}

Substituting expression (4) into the found in [7] expressions of the integral characteristics $\Phi_{s}(t)$ of key functions $\Phi(r, t)$, first we obtain the expressions:

for axial component $H_{z}$ of the vector $\vec{H}$ of magnetic field stress

$$
H_{z}(r, t)=\sum_{i=0}^{3}\left[\sum_{k=1}^{2} \sum_{n=1}^{N}\left(e^{b_{n}} B_{i k n 1}-e^{p_{k} t} B_{i k n 2}\right)\right] r^{i},
$$

Joule heat

$$
\begin{aligned}
& Q(r, t)=\frac{1}{\sigma} \sum_{i=1}^{3} \sum_{j=1}^{3} \sum_{k_{1}=1}^{2} \sum_{k_{2}=1}^{2} \sum_{n_{1}=1}^{N} \sum_{n_{2}=1}^{N} i j\left(c_{i j k_{1} k_{2} n_{1} n_{2} 1} e^{\left(b_{n_{1}}+b_{n_{2}}\right) t}-c_{i j k_{1} k_{2} n_{1} n_{2} 2} e^{\left(p_{k_{1}}+b_{n_{2}}\right) t}\right.
\end{aligned}
$$

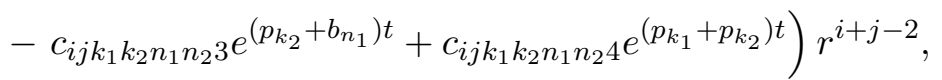

the radial component $F_{r}(r, t)$ of the ponderomotive force vector

$$
\begin{aligned}
& F_{r}(r, t)=-\mu \sum_{i=0}^{3} \sum_{j=1}^{3} \sum_{k_{1}=1}^{2} \sum_{k_{2}=1}^{2} \sum_{n_{1}=1}^{N} \sum_{n_{2}=1}^{N} j\left(c_{i j k_{1} k_{2} n_{1} n_{2} 1} e^{\left(b_{n_{1}}+b_{n_{2}}\right) t}-c_{i j k_{1} k_{2} n_{1} n_{2} 2} e^{\left(p_{k_{1}}+b_{n_{2}}\right) t}\right. \\
& \left.-c_{i j k_{1} k_{2} n_{1} n_{2} 3} e^{\left(p_{k_{2}}+b_{n_{1}}\right) t}+c_{i j k_{1} k_{2} n_{1} n_{2} 4} e^{\left(p_{k_{1}}+p_{k_{2}}\right) t}\right) r^{i+j-1} .
\end{aligned}
$$

Here

$$
\begin{aligned}
& B_{i k n 1}=\frac{a_{i 1} B_{1 n}^{*}(k)+a_{i 2} B_{2 n}^{*}(k)}{b_{n}-p_{k}}+A_{n}\left(a_{i 3}+a_{i 4}\right), \quad B_{i k n 2}=\frac{a_{i 1} B_{1 n}^{*}(k)+a_{i 2} B_{2 n}^{*}(k)}{b_{n}-p_{k}}, \\
& B_{s n}^{*}(k)=\left(B_{s 1}(k)+B_{s 2}(k)\right) A_{n}, \\
& C_{i j k_{1} k_{2} n_{1} n_{2} 1}=B_{i k_{1} n_{1} 1} B_{j k_{2} n_{2} 1}, \quad C_{i j k_{1} k_{2} n_{1} n_{2} 2}=B_{i k_{1} n_{1} 2} B_{j k_{2} n_{2} 1}, \\
& C_{i j k_{1} k_{2} n_{1} n_{2} 3}=B_{i k_{1} n_{1} 1} B_{j k_{2} n_{2} 2}, \quad C_{i j k_{1} k_{2} n_{1} n_{2} 4}=B_{i k_{1} n_{1} 2} B_{j k_{2} n_{2} 2} ;
\end{aligned}
$$

$p_{k}$ - the roots of the characteristic equation corresponding to the equation (6) in the Laplace transforms; $b_{n 1}, b_{n 2}$ are coefficients corresponding to the coefficients in the expression (4); $p_{k 1}, p_{k 2}$ correspond to the roots $p_{k}$; coefficients $a_{i 1} \div a_{i 4}$ correspond to the coefficients in the representation of the function $H_{z}(r, t)=\sum_{i=0}^{3}\left[a_{i 1} H_{z 1}(t)+a_{i 2} H_{z 2}(t)+a_{i 3} H_{z}^{+}(t)+a_{i 4} H_{z}^{-}(t)\right] r^{i}$; expressions $B_{s 1}(k), B_{s 2}(k)$ and $A_{n}$ depend on the roots $b_{n 1}$.

According to the found expressions (18)-(19) on the basis of the general solution of the interconnected system of equations (19) we write expressions of integral characteristics $T_{s}(t)$ and $U_{r s}$ of temperature and radial displacements

$$
\begin{aligned}
T_{1}(t)= & \sum_{\alpha=1}^{6} \sum_{i=1}^{3} \sum_{j=1}^{3} \sum_{k_{1}=1}^{2} \sum_{k_{2}=1}^{2} \sum_{n_{1}=1}^{N} \sum_{n_{2}=1}^{N}\left(\frac{1}{\sigma \lambda} i j\left(A_{2}\left(p_{\alpha}\right) \gamma_{i j 2}-A_{1}\left(p_{\alpha}\right) \gamma_{i j 1}\right)\right. \\
+ & \left.\mu \beta_{4}\left[A_{3}\left(p_{\alpha}\right) \gamma_{i j 2}-A_{4}\left(p_{\alpha}\right) \gamma_{i j 3}\right] j\right) \\
\times & {\left[c_{i j k_{1} k_{2} n_{1} n_{2} 1} \frac{e^{\left(b_{n 1}+b_{n_{2}}\right) t}-e^{p_{\alpha} t}}{\left(b_{n 1}+b_{n_{2}}\right)-p_{a}}-c_{i j k_{1} k_{2} n_{1} n_{2} 2} \frac{e^{\left(p_{n 1}+b_{n_{2}}\right) t}-e^{p_{\alpha} t}}{\left(p_{n 1}+b_{n_{2}}\right)-p_{a}}\right.} \\
& \left.\quad-c_{i j k_{1} k_{2} n_{1} n_{2} 3} \frac{e^{\left(p_{n 1}+b_{n_{2}}\right) t}-e^{p_{\alpha} t}}{\left(p_{n 1}+b_{n_{2}}\right)-p_{a}}+c_{i j k_{1} k_{2} n_{1} n_{2} 4} \frac{e^{\left(p_{n 1}+b_{n_{2}}\right) t}-e^{p_{\alpha} t}}{\left(p_{n 1}+b_{n_{2}}\right)-p_{a}}\right],
\end{aligned}
$$

Mathematical Modeling and Computing, Vol.5, No. 1, pp. 48-55 (2018) 


$$
\begin{aligned}
& T_{2}(t)=\sum_{\alpha=1}^{6} \sum_{i=1}^{3} \sum_{j=1}^{3} \sum_{k_{1}=1}^{2} \sum_{k_{2}=1}^{2} \sum_{n_{1}=1}^{N} \sum_{n_{2}=1}^{N}\left(\frac{1}{\sigma \lambda} i j\left(A_{5}\left(p_{\alpha}\right) \gamma_{i j 1}-A_{6}\left(p_{\alpha}\right) \gamma_{i j 2}\right)\right. \\
& \left.+\mu \beta_{4}\left[A_{7}\left(p_{\alpha}\right) \gamma_{i j 2}-A_{8}\left(p_{\alpha}\right) \gamma_{i j 3}\right] j\right) \\
& \times\left[c_{i j k_{1} k_{2} n_{1} n_{2} 1} \frac{e^{\left(b_{n 1}+b_{n_{2}}\right) t}-e^{p_{\alpha} t}}{\left(b_{n 1}+b_{n_{2}}\right)-p_{a}}-c_{i j k_{1} k_{2} n_{1} n_{2} 2} \frac{e^{\left(p_{n 1}+b_{n_{2}}\right) t}-e^{p_{\alpha} t}}{\left(p_{n 1}+b_{n_{2}}\right)-p_{a}}\right. \\
& \left.-c_{i j k_{1} k_{2} n_{1} n_{2} 3} \frac{e^{\left(p_{n 1}+b_{n_{2}}\right) t}-e^{p_{\alpha} t}}{\left(p_{n 1}+b_{n_{2}}\right)-p_{a}}+c_{i j k_{1} k_{2} n_{1} n_{2} 4} \frac{e^{\left(p_{n 1}+b_{n_{2}}\right) t}-e^{p_{\alpha} t}}{\left(p_{n 1}+b_{n_{2}}\right)-p_{a}}\right] \text {, } \\
& U_{r 1}(t)=\sum_{\alpha=1}^{6} \sum_{i=1}^{3} \sum_{j=1}^{3} \sum_{k_{1}=1}^{2} \sum_{k_{2}=1}^{2} \sum_{n_{1}=1}^{N} \sum_{n_{2}=1}^{N}\left(\frac{1}{\sigma \lambda} i j\left(A_{10}\left(p_{\alpha}\right) \gamma_{i j 2}-A_{9}\left(p_{\alpha}\right) \gamma_{i j 1}\right)\right. \\
& \left.+\mu \beta_{4}\left[A_{11}\left(p_{\alpha}\right) \gamma_{i j 2}-A_{12}\left(p_{\alpha}\right) \gamma_{i j 3}\right] j\right) \\
& \times\left[c_{i j k_{1} k_{2} n_{1} n_{2} 1} \frac{e^{\left(b_{n 1}+b_{n 2}\right) t}-e^{p_{\alpha} t}}{\left(b_{n 1}+b_{n 2}\right)-p_{a}}-c_{i j k_{1} k_{2} n_{1} n_{2} 2} \frac{e^{\left(p_{n 1}+b_{n 2}\right) t}-e^{p_{\alpha} t}}{\left(p_{n 1}+b_{n 2}\right)-p_{a}}-\right. \\
& \left.-c_{i j k_{1} k_{2} n_{1} n_{2} 3} \frac{e^{\left(p_{n 1}+b_{n 2}\right) t}-e^{p_{\alpha} t}}{\left(p_{n 1}+b_{n 2}\right)-p_{a}}+c_{i j k_{1} k_{2} n_{1} n_{2} 4} \frac{e^{\left(p_{n 1}+b_{n 2}\right) t}-e^{p_{\alpha} t}}{\left(p_{n 1}+b_{n 2}\right)-p_{a}}\right] \text {, } \\
& U_{r 2}(t)=\sum_{\alpha=1}^{6} \sum_{i=1}^{3} \sum_{j=1}^{3} \sum_{k_{1}=1}^{2} \sum_{k_{2}=1}^{2} \sum_{n_{1}=1}^{N} \sum_{n_{2}=1}^{N}\left(\frac{1}{\sigma \lambda} i j\left(A_{13}\left(p_{\alpha}\right) \gamma_{i j 1}-A_{14}\left(p_{\alpha}\right) \gamma_{i j 2}\right)\right. \\
& \left.+\mu \beta_{4}\left[A_{15}\left(p_{\alpha}\right) \gamma_{i j 2}-A_{16}\left(p_{\alpha}\right) \gamma_{i j 3}\right] j\right) \\
& \times\left[c_{i j k_{1} k_{2} n_{1} n_{2} 1} \frac{e^{\left(b_{n 1}+b_{n 2}\right) t}-e^{p_{\alpha} t}}{\left(b_{n 1}+b_{n 2}\right)-p_{a}}-c_{i j k_{1} k_{2} n_{1} n_{2} 2} \frac{e^{\left(p_{n 1}+b_{n 2}\right) t}-e^{p_{\alpha} t}}{\left(p_{n 1}+b_{n 2}\right)-p_{a}}-\right. \\
& \left.-c_{i j k_{1} k_{2} n_{1} n_{2} 3} \frac{e^{\left(p_{n 1}+b_{n 2}\right) t}-e^{p_{\alpha} t}}{\left(p_{n 1}+b_{n 2}\right)-p_{a}}+c_{i j k_{1} k_{2} n_{1} n_{2} 4} \frac{e^{\left(p_{n 1}+b_{n 2}\right) t}-e^{p_{\alpha} t}}{\left(p_{n 1}+b_{n 2}\right)-p_{a}}\right] .
\end{aligned}
$$

Here $A_{1}\left(p_{\alpha}\right) \div A_{16}\left(p_{\alpha}\right)$ are the corresponding algebraic adjuncts of the system of four algebraic equations that corresponds to the integrated system of equations (9) (according to the formula (16)) in relation to the defining functions that are the Laplace transforms of integral characteristics $T_{s}(t)$ and $U_{r s}$ of temperature and radial displacements; expressions $p_{n 1}, p_{n 2}$, correspond to the roots $p_{k} ; p_{\alpha}$ of the algebraic equation of the 6th order corresponding to the equation $\Delta(p)=0$, where $\Delta(p)$ is the determinant of the system of four algebraic equations for the Laplace transform of integral characteristics $T_{s}(t)$ and $U_{r s}$;

$$
\gamma_{i j 1}=\frac{r_{1}^{i+j+1}-r_{0}^{i+j+1}}{i+j+1}, \quad \gamma_{i j 2}=\frac{r_{1}^{i+j+2}-r_{0}^{i+j+2}}{i+j+2}, \quad \gamma_{i j 3}=\frac{r_{1}^{i+j+3}-r_{0}^{i+j+3}}{i+j+3} .
$$

According to the well-known expressions (20)-(23) of the integral characteristics $T_{s}(t)$ and $U_{r s}$, we write the expressions of temperature $T$ and radial displacements $U_{r}$ in the form

$$
T(r, t)=\sum_{\alpha=0}^{3}\left[b_{\alpha 1} T_{1}(t)+b_{\alpha 2} T_{2}(t)\right] r^{\alpha}
$$




$$
U_{r}(r, t)=\sum_{\beta=0}^{3}\left[c_{\beta 1} U_{r} 1(t)+c_{\beta 2} U_{r 2} 1(t)+c_{\beta 3} T\left(r_{0}, t\right)+c_{\beta 4} T\left(r_{1}, t\right)\right] r^{\beta} .
$$

Here, $b_{\alpha 1} \div b_{\alpha 2}, c_{\beta 1} \div c_{\beta 4}$ are the numerical coefficients depending on the physical and mechanical characteristics of the material of the cylinder and its geometrical parameters $r_{0}$ and $r_{1}$.

According to the found expressions (24)-(25) of temperature $T$ and radial displacement $U_{r}$, we write the expressions of the radial $\sigma_{r r}$, circular $\sigma_{\varphi \varphi}$ and axial $\sigma_{z z}$ components of the stress tensor according to formulas (13). Thus, we obtain a general solution of the connected problem of thermomechanics for the considered conductive cylinder under the influence of IEMP with amplitude modulation of the aforesaid characteristic types.

\section{Conclusion}

Using the approximation of the axial component of the magnetic field stress vector, temperature and radial component of the displacement vector by cubic polynomials in the radial variable, the general solution of the connected dynamic problem of thermomechanics for a long hollow electroconductive cylinder under the action of impulsed electromagnetic fields with amplitude modulation was obtained in a simple analytical form. The obtained solution is the basis for the computer analysis of the influence of such characteristic fields on the process of thermoelastic energy dissipation in the conductive hollow cylinder, which is a constructive element of many devices, as well as sensors of electromagnetic radiation of the radio frequency range.

[1] Batygin J., Lavynskyy V., Braams J., Hymenko I. Impulsnyje magnitnyje polja dlja progressivnyh tehnologij. Harkov, Most-Tornado Publ. (2003), (in Russian).

[2] Herlah F. Sylnyje i sverhsylnyje magnitnyje polja i ih prymjenjenyje. Moskva, Mir. (1988), (in Russian).

[3] Honorovskij I. Radiotechnical chains and signals. Moscow, Radio and communications (1986), (in Russian).

[4] Podstrygach J. et al. Tjermouprugost electroprovodnyh tel. Kyev, Naukova Dumka (1977), (in Russian).

[5] Hachkevych O., Musij R., Tarlakovskii D. Thermomechanics of Nonferromagnetic Electroconductive Bodies at Effect of Impulse Electromagnetic Fields with Modulation Amplitude. Lviv, SPOLOM (2011), (in Ukrainian).

[6] Musij R. Dynamichni zadachi thermomechaniky electroprovidnyh til kanonichnoji formy. Lviv, Rastr-7 (2010), (in Ukrainian).

[7] MusijR., Drohomyretska Kh., Oryshchyn O. Solution of coupled problem of thermomechanics for electroconductive hollow cylinder under non-stacionary electromagnetic action. Mathematical Modeling and Computing. 4 (1), 69-77 (2017). 


\title{
Розв'язок зв'язаної задачі термомеханіки для довгого порожнистого електропровідного циліндра за дії імпульсного електромагнітного поля з модуляцією амплітуди
}

\author{
Мусій Р., Дрогомирецька Х., Клапчук М., Орищин О., Наконечний Р. \\ Національний університет «Львівсъка політехніка», \\ вул. С. Бандери, 12, 79013, Лъвів, Україна
}

\begin{abstract}
Використовуючи апроксимацію осьової компоненти вектора напруженості магнітного поля, температури та радіальної компоненти вектора переміщень кубічними поліномами за радіальною змінною, отримано загальний розв'язок зв'язаної динамічної задачі термомеханіки для довгого порожнистого електропровідного циліндра за дії імпульсних електромагнітних полів з модуляцією амплітуди у простій аналітичній формі. Знайдений розв'язок є основою для комп'ютерного аналізу впливу таких полів характерних типів на процес термопружного розсіювання енергії в електропровідному порожнистому циліндрі, що є конструктивним елементом багатьох приладів і пристроїв, а також сенсорів електромагнітного випромінювання радіочастотного діапазону.
\end{abstract}

Ключові слова: імпульсне електромагнітне поле з модуляцією амплітуди, режим згасної синусоӥди, електропровідний порожнистий ииліндр, зв'язана задача термомеханіки, кубічна апроксимація.

2000 MSC: $74 \mathrm{H} 10$

Удк: 539.3 